\title{
On-line monitorization in a decarbonator-settling tank for water treatment
}

\author{
A. Tijero, A. Moral, J. Tijero, A. Blanco \& C. Negro \\ Department of Chemical Engineering, \\ Universidad Complutense de Madrid, Spain
}

\begin{abstract}
The objective of this work is the on-line control of the solid-liquid separation process in a water treatment plant using a focused beam reflectance measurement sensor (FBRM) in order to improve the coagulation, precipitation and flocculation of this plant. A previous study of the system is carried out in order to analyze the possible influence of the external variables on the floc mean chord size though of the monitorization of the flocculation tank. The formation of particle aggregates is the product of the addition of an inorganic flocculant $\left(\mathrm{FeCl}_{3}\right)$ with a subsequent treatment with an organic synthetic flocculant (anionic polyacrilamide) that determine the formed floc properties. The FBRM study of the variations of the mean chord size realised after the changes in the system show an improvement in flocculant diffusion and a greater phase contact. The final objective is to improve the calcium carbonate precipitation conditions, to reduce the membrane fouling and avoid the deposit formation in the plant surface. The trials carried out a characterization of the waters before and after changes in the system in order to establish whether the final properties of the water fulfil the parameters required for its posterior use. The results obtained show that the measurement system FBRM is an on-line sensor that is good enough to be used as a control and prediction method in the water treatment industries. Furthermore, the relations between the data obtained by the sensor and the properties of the water after the depuration allow control of the outlet water.
\end{abstract}

Keywords: flocculation, coagulation, FBRM control on-line, river water treatment. 


\section{Introduction}

For the best distribution of electric power, new Combined Cycle Power Plants (CCPP) are installed near consumer centres. Due to their strategic location, in many power plants the water supply is from a river polluted by wastewater and by municipal and industrial wastewater treatment plants' effluents.

The object of this work is the optimization of the water pre-treatment plant in a CCPP, where raw water is supplied by a river that has a basin with dense population and industrialization areas, and to obtain by this pre-treatment water with the adequate characteristics needed for use in the refrigeration towers.

The pre-treatment process can be designed as "enhanced coagulation and enhanced precipitative softening", which refers to the process of improving the removal of natural organic matter (OM) compared with other conventional coagulation of softening water treatment processes.

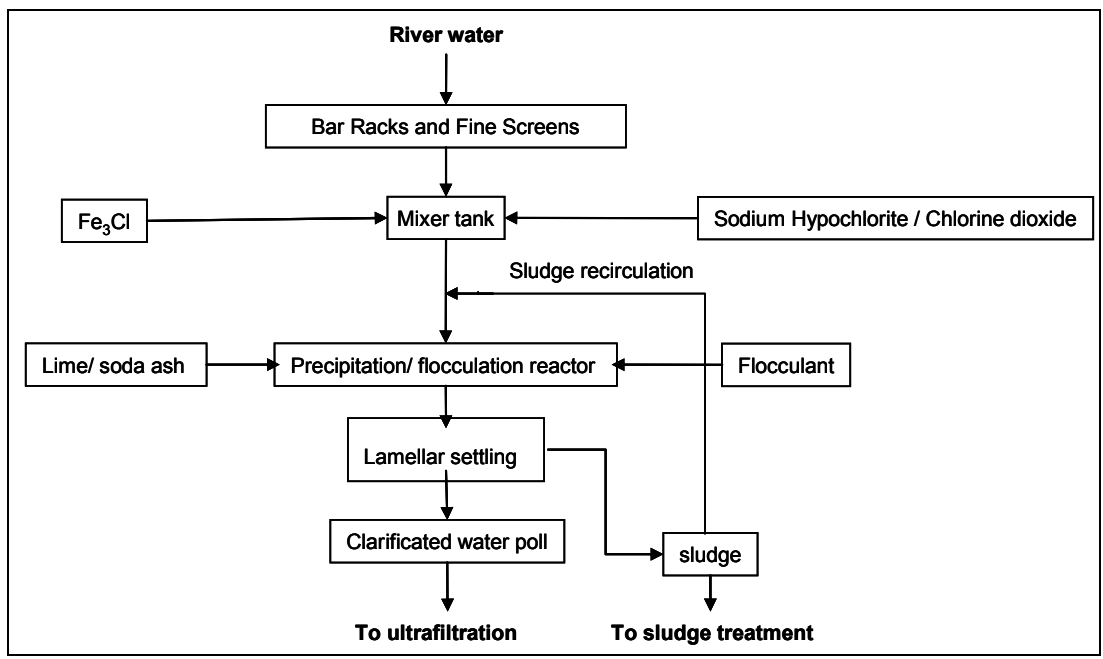

Figure 1: $\quad$ Plant block diagram.

In the preliminary step, river water is carried by a channel with a bar rack and screen and pumped to the raw water river basin.

The first step of the physic-chemical treatment is coagulation with iron trichloride in a mixer tank for organic matter (OM) and removal, and addition of chlorine/chlorine dioxide for OM oxidation and disinfection.

When added to water, iron salts dissociate and react to yield hydrolysis products. As first evidenced by Mattson in 1928, these hydrolysis products form the coagulant species that remove turbidity and colour during water treatment [1]. The hydrolysis of $\mathrm{FeCl}_{3}$ proceeds with monomers, dimmers, double corner trimers, and polycations that consist in the arrangement of $24 \mathrm{Fe}$ atoms in a B$\mathrm{FeOOH}$ local structure [2]. Further neutralization of the Fe solution induces the 
association of $\mathrm{Fe}_{24}$ polycations within fractal clusters [3]. Unlike river waters, municipal sewage provides a system with abundant organic matter and complexing anions that should extend the concentration range in which hydrolyzing coagulant species interact with the raw water content [4]. The removal of this organic matter from the bulk water can occur by direct precipitation or by adsorption of the organic matter onto metal hydroxides [4].

The second step is precipitative softening carried out in a continuous stirredtank reactor (CSTR), with hydroxide ions (as $\mathrm{Ca}(\mathrm{OH})_{2}$ ) addition for the carbonate speciation to $\mathrm{CO}_{3}{ }^{-2}$ which facilitates the precipitation of $\mathrm{CaCO}_{3}$. This process generally takes place at a $\mathrm{pH}$ of 10 . Removal of magnesium hardness is caused by the precipitation of $\mathrm{Mg}(\mathrm{OH})_{2}$ which generally takes place at a $\mathrm{pH}$ of 10.5 or higher. Depending on the characteristics of the source water and the relative concentrations of calcium and magnesium ions and carbonate and noncarbonate ions, the amount of lime and soda ash required for precipitative softening may vary. Rivers with strong seasonal variations of flow with water composition of magnesium salt in summer can require a necessary soda ash addition for magnesium precipitation.

In the third stage the flocculation process is carried out. Flocculant is added to the precipitation/flocculation reactor. In this case we have a dual system defined by a complex flocculation, which is by a flocculation combined by a previous coagulation mechanism. These traditional dual systems involve the use of two different polymers, a high molecular weight anionic polymer (anionic polyacrilamide) and a low or middle molecular weight high density cationic polymer, or a metallic cation $\left(\mathrm{FeCl}_{3}\right)$. This mechanism involves the adsorption of the cationic polymers or metallic cations into the negative colloidal surface, forming cationic patches, and the interaction between the high molecular weight polymer and positive charges or previous formed patches form a bridging between the colloidal particles. The bridging mechanism between the colloidal particles by an electrostatic-patch is show in figure 2 .

The result of this kind of mechanism is flocs that combine the resulting properties of the flocs formed by a patch and bridging flocculations. The flocs are quite resistance and a partial re-flocculation readily occurs under low shear conditions. However, the efficiency of these systems depends on the order of the

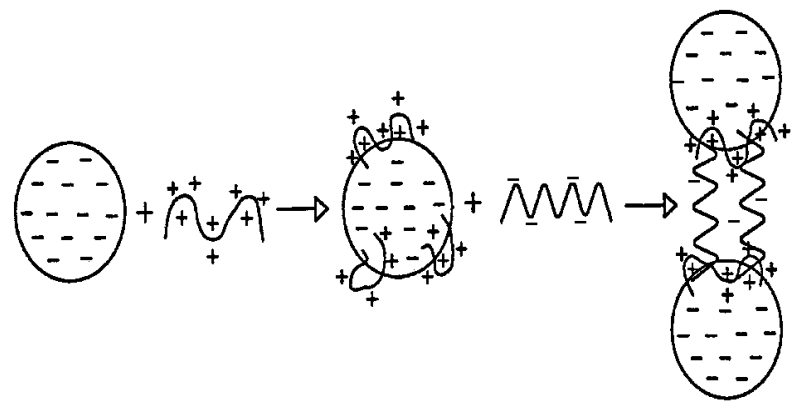

Figure 2: Bridging mechanism by electrostatic patch. 
additions of the components and of the time interval between additions [5]. In our industrial level application the depuration entails an ultra-filtration process and due to that the previous particle flocculation is vital because it increases membrane lifetime and the process efficiency.

The flocs formation into precipitation/flocculation reactor was studied by monitoring of the flocs size with a FBRM sensor. These measures, in real time, are related to the process variables. The control set-points of these process variables for chemicals dosification is established from supply river water characteristic.

This paper tries to evaluate the possibility to carry out modifications in the pre-treatment plant to reduce to the minimum the employment of chemicals as well as to solve the problems of the inlay and the adherence. These modifications can be in the treatment process or installation revamping

Finally, the objective is, to study the flocs formation and its evolution along successive plant steps. A preliminary study shows what main phenomena occur inside the precipitation/flocculation stirred tank; for this motive the selected localization for flocculation probe is immersed in the turbulence zone.

The fundaments of measurement with the FBMR sensor will be explained in 2.1. The results of the flocs' measurements were compared with the variables that affect the coagulation-flocculation.

Supply water is also a characterized and the outlet water from the settling pond, before and after of the system modifications, with the objective to obtain enough data to evaluate if the final characteristics of the water fulfil the specified parameters for use as cooling tower water, bearing in mind the seasonal variation of the river water characteristic for several time periods.

\section{Experimental}

\subsection{FBRM probe description and location}

The methodology to monitor flocculation is based on using a focused beam reflectance measurement system, FBRM M500P, manufactured by Lasentec Mettler Toledo, Seattle, USA. The FBRM technique provides the chord length distribution of the particles in the suspension in real time. This distribution depends on the shape, size and concentration of particles [6].

The FBRM measurement principle, as shown in figure 3, is based on backward light scattering. A laser beam is coupled to an immersible probe via an optical fibre. This laser beam is deviated from the probe's central axis and focussed into a disperse medium with an optical conduit. When this laser beam intersects with a particle, light scattering occurs. A certain fraction of the light is scattered back into the system. This back scattered light is coupled via a beam splitter to a second fibre and conduced to a detector [7]. The rotational velocity of the laser is constant. The time span in which back scattering is detected is therefore directly proportional to the path length of the laser on the particle. It is assumed that the particle velocity is small compared to the laser rotational velocity. The length of the laser path on the particle is therefore proportional to 


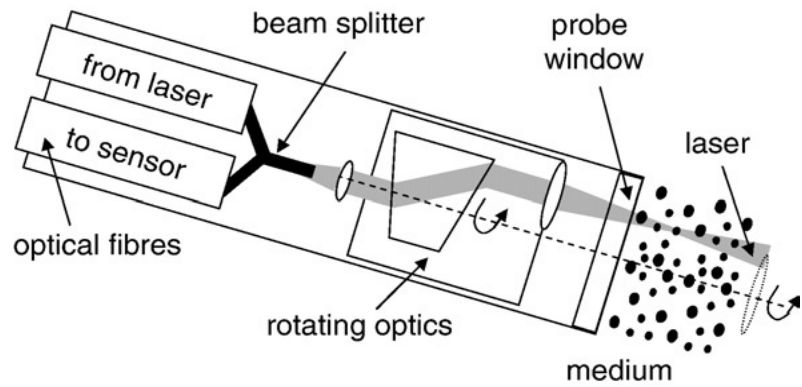

Figure 3: $\quad$ Schematic drawing of a FBRM probe.

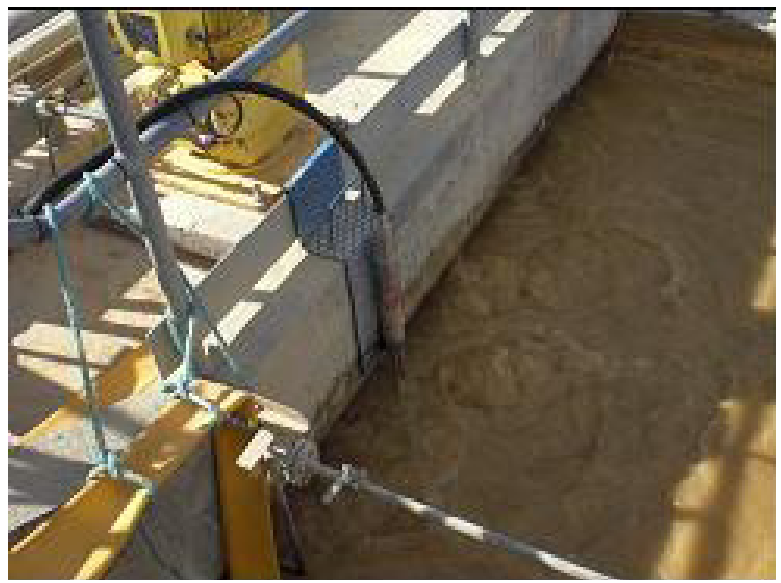

Figure 4: Location of the FBRM.

the time span in which scattering is detected. This path length is called a chord length.

Depending on the laser position, different chord lengths are measured even for a single particle. Those chord lengths are generally different from any characteristic particle length [8].

The detail methodology to study flocculation processes and floc properties and the principles of the measurements are described in previous papers $[9,10]$.

The right selection of the probe location with respect to the full flow sheet of the process and the orientation inside the tank is essential to obtain accurate data. It was decided to install the FBRM after coagulant addition in the flocculation tank. The location of the FBRM is show in the figure 4.

The FBRM probe is immersed into the precipitation/flocculation tank, fixed on the bridge of the agitator, as shown in figure 3. This zone inside of the flocculation tank has height agitation, without bubbles, to obtain representative data from the system and to keep adherents particles from the lens off the FBRM. This tank is a crucial zone of the depuration process because inside it takes place the precipitation of calcium carbonate and magnesium carbonate/ 
magnesium hydroxide, the growth of precipitate particles for recirculation of part of the sludge and the addition of polyelectrolyte to the water previously coagulated to produce a complex flocculation.

\subsection{Recording time optimization}

In the selection of the recording time of particle size distribution we have to take into account that the shorter the measuring time, the greater the sensibility will be, although, at the same time any natural "noise" from the measurement will be recorded. Moreover, the management of very short measuring times entails having to work with a great amount of information. All the data presented correspond to measurements carried out inside the flocculation tank with the purpose of optimizing the measuring time of this study system. The recording time optimization data is show in the figure 5.

In recording times of 30 minutes the graphic have lines with few peaks and this show that three lines are good to obtain a global development, however we lose important information for shorter intervals. For times lower than 10 minutes ( 5 and 2 minutes) the results obtained are very difficult to interpret because the natural noise from the measurement meddles significantly with the great amount
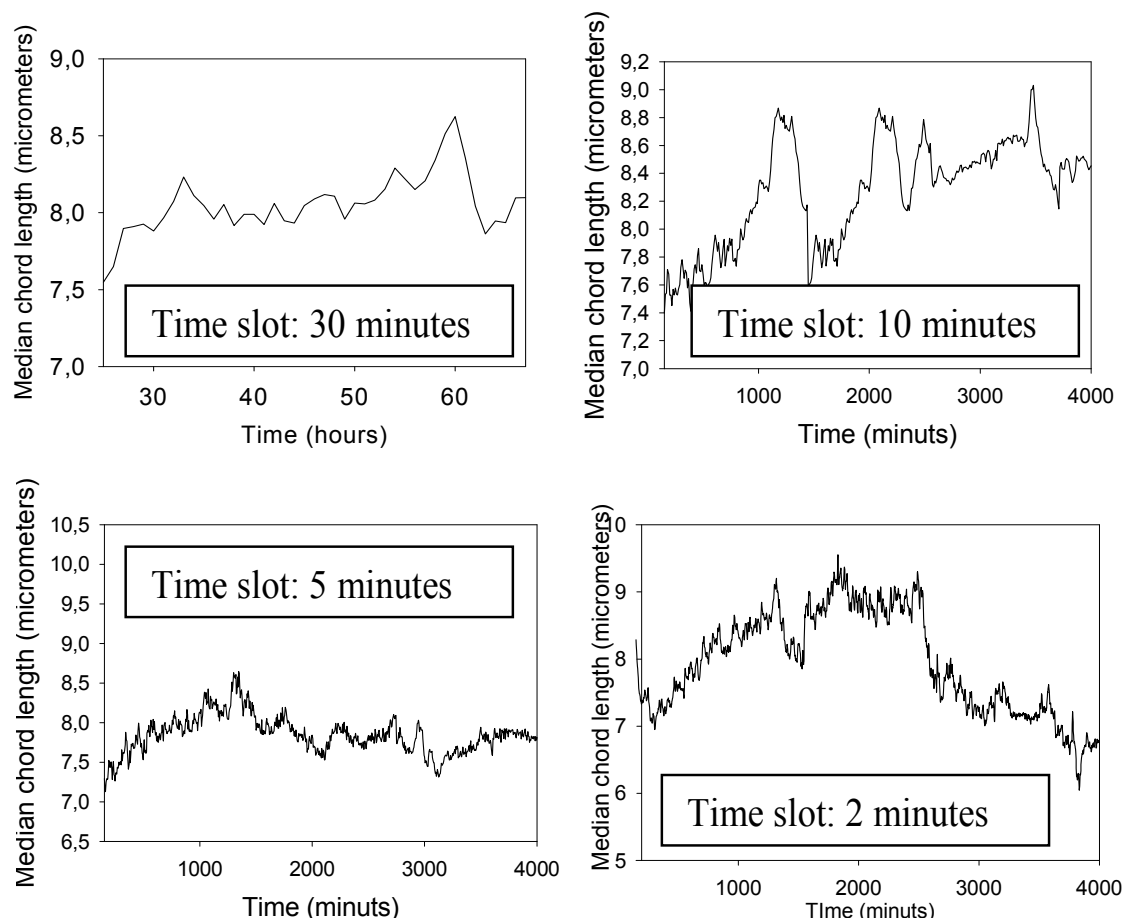

Figure 5: $\quad$ Recording time optimization data. 
of information obtained. Best time interval measurement of the particle size distribution is 10 minutes. This interval permits to obtain a very stable measurement and delayer time is low compared with change rate in the system.

\section{Results and discussion}

In the industrial pre-treatment plant operation, all process variables are controlled, also are analysed and monitoring numerous parameters. In this work the selected process parameters for optimization are:

Point and amount of polyelectrolyte dosified

Sludge recirculation

Flocs size as long of cord

Treatment efficiency is giving for:

Turbidity, NTU

Total organic carbon, TOC

Hardness as total and calcium hardness, in $\mathrm{mg} / \mathrm{L}$ of $\mathrm{Ca} \mathrm{CO}_{3}$

\subsection{Water characterization}

The analytical parameters systematically determined in the pre-treatment plant are:

Calcium, magnesium, bicarbonates, carbonates, hydroxides, chlorides, sulphates, nitrates, phosphates, fluorides, nitrites, $\mathrm{pH}$, conductivity, turbidity, TOC, COD, anionic detergents, ammonia, silica solved and total, chlorine free , chlorine demand, solids (dissolved, suspended and total), iron, manganese and aluminium

The water samples obtained in different points of the plant present a common characteristic, their anionic charge. Water cationic demands are determined in different points of process.

The flocculant used during this work realization is of medium molecular weight, and moderately anionic. The results obtained from these samples show a very low variability (figure 6).

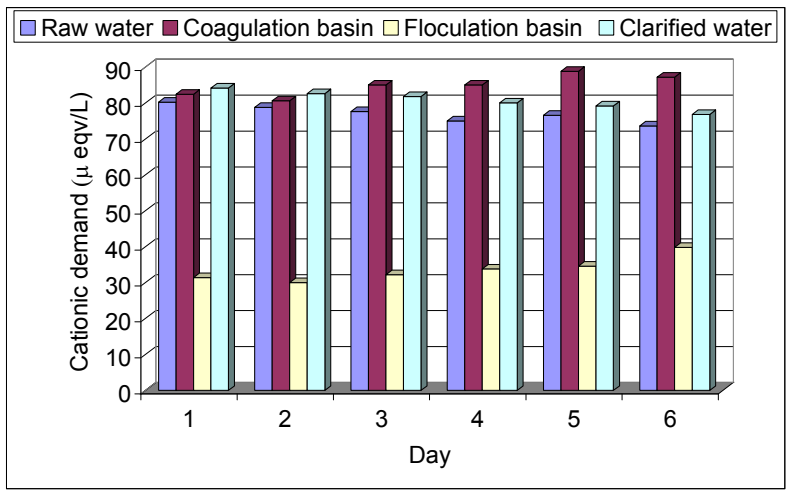

Figure 6: Cationic demands of process water. 


\subsection{Correlating the effect of flocculant dosages with sensor data}

Several plant trials were carried out with different polyacrilamide concentrations and without change the rest of the parameters. The on-line measure system FBRM situated in the flocculation tank detected that when there is an increase in the polyacrilamide dose the particle mean chord size increase. The optima flocculant dose needed to obtain a maximum mean chord size was previously calculate by the star-up supplier. However, it is observed that when there is an increase of the dose with respect to the recommended dose the mean chord size increase and this is a probe that there is problem with the dosification or the homogenization.

After a detailed study of the plant, it is detected in the second mix chamber that the dosification of flocculant is carried out in a far away zone of the propeller that permits the homogenization of the system by stirring, and because of that the contact between the flocculant, the environment and the lime is not carried out of adequate form. Because of that it is necessary to make a change in the flocculant addiction pipe placing it in the maximum agitation zone in order to improve the contact between phases.

\subsection{Monitoring the effect of system changes}

After the changes in the process, the average chord size increases, that is an indication of a better precipitative softening. As well, it is observed that the biggest flocs have more stability, that is, they suffer less size variation with the time the next figure shows that, after the changes in the system, the mean chord size rise from about $7 \mu \mathrm{m}$ values to $14 \mu \mathrm{m}$ that is a betterment of the system.

\subsection{Correlating sensor data with water properties}

Changes realised in addition point and dosification of flocculant and in sludge recirculation can be appreciated in floc size and floc stability shown in figure 7 . This best flocculation is related with selected treatment analytical parameters.

\subsubsection{Turbidity}

This parameter reflects the efficiency of flocculation. Raw river water has very different turbidity, between 10 and 35 NTU, the graphics shown in figure 8 show the changes in the systems before and after of modifications in the system.

Turbidity reduction efficiency is about $80 \%$ previous to a plant's modifications and get to $90 \%$ after these changes.

Clarified water NTU is given for lineal equations.

Previous at changes in process:

After changes in process:

$$
\text { NTUclarified water }=0,197 N T U \text { raw water } \text {. }
$$

$$
\text { NTUclarified water }=0,102 N T U \text { raw water } \text {. }
$$




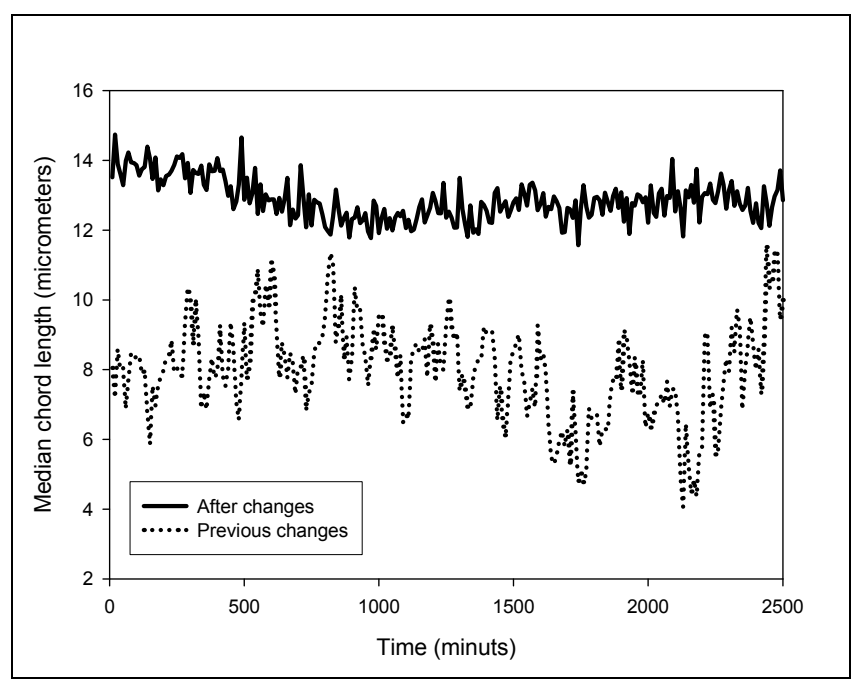

Figure 7: Mean chord size previous and after the changes in the system.

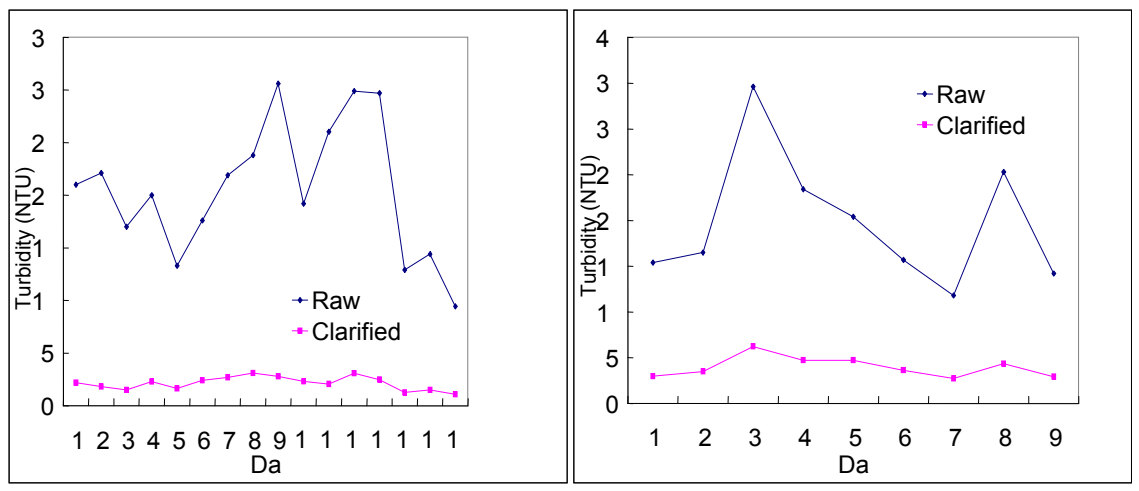

Figure 8: Comparison of turbidity of the raw water with clarified water, before (to the left side) and after (to the right) process modifications.

\subsubsection{TOC}

Enhanced coagulation is a treatment technique that has the purpose of removing organic matter $(\mathrm{OM})$ to reduce the formation of Disinfection By-product DBPs.

Enhanced softening refers to the process of obtaining improved removal of MO, DBP precursors, by precipitative softening. The analytical parameter adopted is TOC. Figure 9 shows the variability of raw water TOC.

Coagulation and precipitative softening, before treatment modifications, has an efficiency of TOC reduction in clarified water of about $35 \%$ of raw water TOC. After modifications TOC reduction is about $50 \%$. 

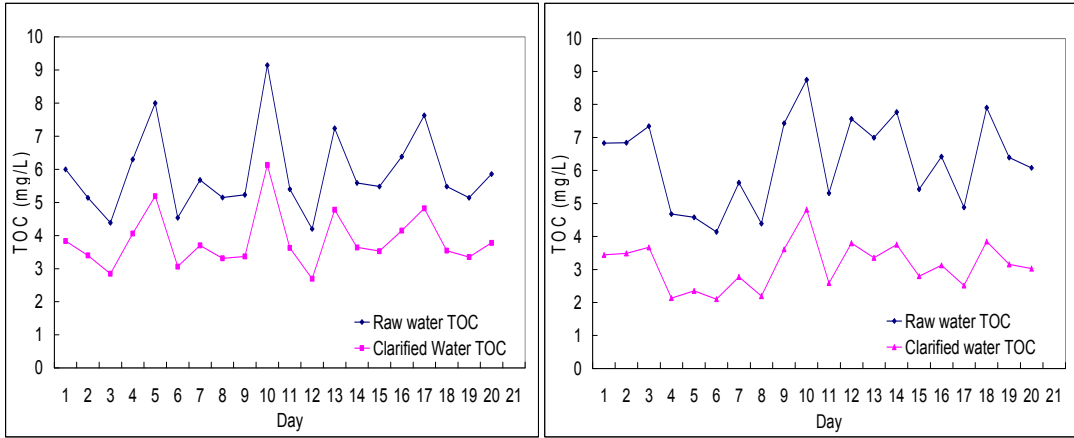

Figure 9: Comparison of the raw water TOC with clarified water TOC, before (to the left side) and after (to the right) process modifications.

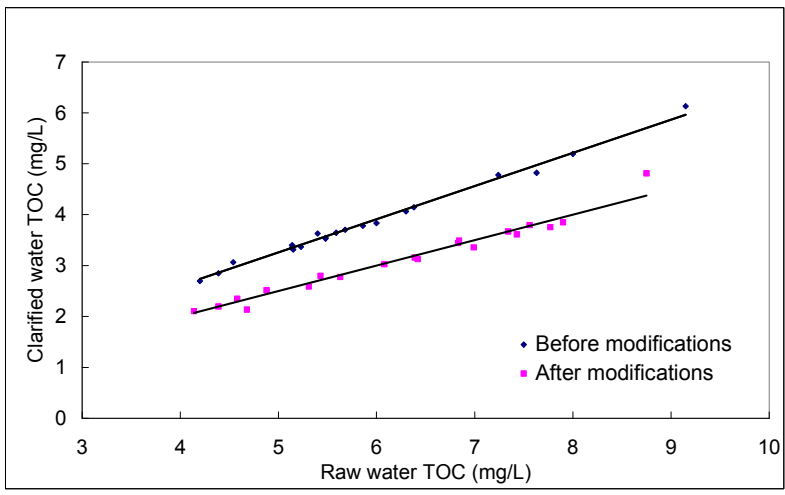

Figure 10: Clarified water TOC vs. raw water TOC.

Clarified water TOC is related to raw water TOC by the lineal equations. Previous at modifications:

After modifications:

$$
\text { TOC } \text { clarified water }=0,64 T O C_{\text {raw water, }} R^{2}=0,98
$$

$$
\text { TOC } C_{\text {clarified water }}=0,49 T O C_{\text {raw water }}, R^{2}=0,96
$$

Figure 10 show the clarified water TOC versus raw water TOC. TOC reduction efficiency of treatment before modifications is about $36 \%$ of TOC of water inlet. TOC reduction efficiency rise to about $50 \%$ after process modifications

\subsubsection{Hardness}

Influent hardness has high variability, and softening treatment is not always able to get the maximum specified calcium hardness $360 \mathrm{mg} / \mathrm{L}$ as calcium carbonate and $480 \mathrm{mg} / \mathrm{L}$ as calcium carbonate of specified maximum total hardness. 

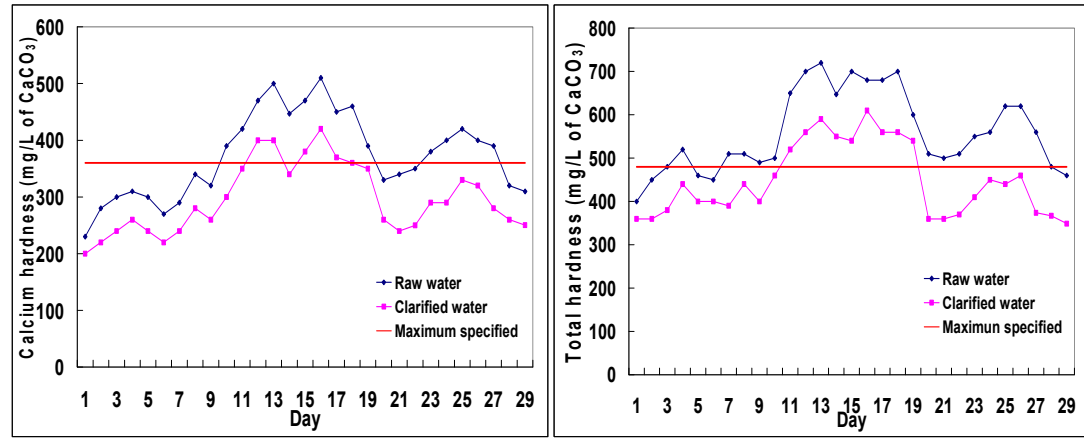

Figure 11: Comparison of calcium hardness (left-hand side) and total hardness (right-hand side) of the raw water with clarified water.

The graphics in figure 11 shows that it is suitable to be more efficiency in the water softening. Process changes are operating after the $20^{\text {th }}$ day, but hardness values of clarified water are not sufficiently low. For more hardness reduction it is necessary to make changes in $\mathrm{pH}$, different lime and soda ash addition and, also, the addition of another kind of flocculant, preferment cationic, in order to get softer water.

\section{Conclusions}

The methodology based on utilization of a focused beam reflectance system of measure FBRM is suitable to supervise process of precipitative softening and flocculation.

Modifications in process are related to floc size and this floc size with the treatment analytical parameters, as turbidity, TOC and hardness.

Changes in the dosage point and dosage amount of flocculant improved the mix and diffusion, the fixation on the floc surface, and the physical-chemical adsorption equilibrium achieving between adsorbed flocculant and the flocculant in solution.

These process modifications are important because the flocculant left in the water, increasing membranes fouling and fixing into the surfaces, forming appreciable velocity growth of incrustation

\section{References}

[1] Mattson, S., Cataphoresis and the electrical neutralization of colloidal material. Journal of Physical Chemical, 32, pp. 1532-1552, 1928.

[2] Bottero, J.Y., Manceau, A, Villieras F. \&, Tchoubar D., Structure and mechanism of formation of $\mathrm{FeOOH}(\mathrm{Cl})$ polymers. Langmuir, 10, pp. 316319, 1994. 
[3] Tchoubar, D., Bottero, J .Y., Quienne, P, Arnaud, M. Partial hydrolysis of ferric chloride salt. Structural investigation by phonton-correlation spectroscopy and small angle X-ray scattering. Langumir 1991; 7: 398-402.

[4] El Samrani, A. G., Lartiges, B. S., Montargès-Pelletier, E., Kazpard, V., Barrès, O. \& Ghanbaja, J., Clarification of municipal sewage with ferric chloride: the nature of coagulant species, Water research; 38, pp.756-768, 2004.

[5] Csempesz, F., Enhanced flocculation of colloidal dispersions by polymer mixtures. Chemical Engineering Journal, 80, pp 43-49, 2000.

[6] Negro, C., Sánchez, L. M., Fuente, E., Blanco, A. \&. Tijero, J., Polyacrylamide induced flocculation of a cement suspension. Chemical Engineering Science, 61, pp 2522 - 2532, 2006.

[7] Sparks, R. G., Dobbs, C. L., The use of laser backscatter instrumentation for the online measurement of the particle-size distribution of emulsions, Particle \&. Particle System Characterization, 10, pp. 279-289, 1993.

[8] Tadayyon, A. \& Rohani, S., Determination of particle size distribution by Par-Tec (R) 100: modeling and experimental results, Particle \&. Particle System Characterization, 15, pp. 127-135, 1998.

[9] Blanco, A., Fuente, E., Negro, C. \& Tijero, J., Flocculation monitoring: focused beam reflectance measurement as a measurement tool. The Canadian Journal of Chemical Engineering, 80, pp.734-740, 2002.

[10] Blanco, A., Fuente, E., Negro, C. \& Tijero, J., Focused beam reflectant measurement as a tool to measure flocculation. Tappi Journal, 1, pp.14-20, 2002. 